\title{
The London Television Service
}

\begin{abstract}
$\triangle$ MEETING of the Institution of Electrical Engineers held on April 21 was devoted to a series of papers describing the development of the television broadcasting service which has been operated by the British Broadcasting Corporation at the Alexandra Palace station since August 1936. The first paper, by Messrs. T. C. Macnamara and D. C. Birkinshaw entitled "The London Television Service", recalled certain early electrical discoveries which laid the foundations of modern television. The Nipkow scanning disk was invented in 1884 and is still in use in certain systems to-day; while in 1908, A. A. Campbell Swinton described the forerunner of the present-day cathode ray tubes used both for scanning and for reproduction purposes.
\end{abstract}

In 1929, arrangements were made between the B.B.C. and Baird Television, Ltd., for the first regular transmissions from a London station of television programmes of the low-definition type, using 30-line scanning and $12 \frac{1}{2}$ pictures per second. Some five years later, His Majesty's Postmaster - General appointed a committee under the chairmanship of Lord Selsdon to review the development of television and to advise on the conditions under which a public service should be conducted. The recommendations of this committee were put into effect in August 1936, by the inauguration of the London Television Station at Alexandra Palace. After a trial period, in which the technical merits of two systems of high-definition television were compared, the same committee announced in February 1937 that the London station would in future use the Marconi-E.M.I. system with its interlaced scanning with 405 lines and 25 frames per second. The use of interlaced scanning is advantageous in that it has the apparent effect of increasing the picture-repetition frequency to 50 per second, at which no flicker is perceptible to the eye, without increasing the band of modulation frequencies required.

A detailed discussion of the development of this standard of scanning with a specification of the radiated wave-form employed is given in the second of the series of papers, entitled "The Transmitted Wave-form", by A. D. Blumlein. The transmission is of the so-called direct-current type in that there is no fixed average value of the carrier wave amplitude. Under normal running conditions, with no transmitted picture, the 'all-black' condition is represented by the carrier wave amplitude being at 30 per cent of its peak value, the line and frame synchronizing impulses reducing this to zero amplitude at the appropriate intervals. This arrangement of the conditions is claimed to minimize the effect of interference on the synchronism of the received picture. The 'all-white' condition is represented by full modulation at the peak amplitude, so that the vision signals occupy values between 30 per cent and 100 per cent of the radiated carrier. Details of the equipment which has been developed to handle the modulation which arises from this method of transmitting the picture signals are given in the third paper, entitled "Vision Input Equipment", by C. O. Browne. This paper includes a cursory description of the technical features of the equipment, and contains a list of references to more detailed information.
The fourth and last paper of the series was presented by Messrs. N. E. Davis and E. Green under the title "The Radio Transmitter". The vision transmitter at the London station was designed to give a peak output power of $17 \mathrm{kw}$. when a steady condition is maintained corresponding to the transmission of a full white picture. The general design of the transmitter was based on the fundamental principles which have now been in use for some years in com. mercial short-wave communication transmitters, but certain new problems were met in adapting this design to the ultra-short wave-length of $6.7 \mathrm{~m}$. (frequency $45 \mathrm{Mc}$./sec.) required and also to enable it to handle the unusually great modulation bandwidth of $\pm 2.5 \mathrm{Mc}$./sec. The paper gives some details of the circuit, valves and assembly employed at the Alexandra Palace station.

Reverting to the first paper by Macnamara and Birkinshaw, considerable space is devoted to a general description of the London Television Station, with plans of the accommodation and details of the studios and equipment employed for the staging and production of the vision programmes radiated. For outside broadcasts, a fleet of special motor vans has been developed, these carrying respectively a mobile studio, an ultra-short wave transmitter for providing a radio link with Alexandra Palace, and a mobile power supply for the above two vehicles. In addition, a fourth vehicle is used to carry an extensible selfsupporting wooden ladder of the fireman's type, to provide an aerial mast for the local mobile transmitter. Reception from this transmitter is carried out with a radio link receiver installed at Alexandra Palace, but precautions have had to be taken to secure freedom from interference from the main vision transmitter.

To avoid difficulties involved in the operation of such an ultra-short wave radio link, a balanced lowcapacitance cable, primarily designed for television, has been installed between Alexandra Palace and central London, tapping points being provided at frequent intervals along the cable route at what may be considered to be the main points of interest from a television programme point of view. In addition, experiments have been conducted into the use of short lengths of ordinary telephone line whereby extensions may be made from the main television cable.

The latter portion of the paper gives the results of a field strength survey of the radiation from Alexandra Palace, and a contour map illustrates the distribution of the field at distances up to 25 miles from the station. This was the range originally estimated for, but it is now safe to say that good reception can be obtained up to about 35 miles, except in cases where unusually bad interference is encountered. Under exceptionally favourable conditions, good reception has been reported at distances of 40 to 60 miles, and while reception is still possible at much greater distances up to a few hundred miles, this usually does not come up to the standard of reliability which it is desirable to attain in a public broadcasting service.

Altogether these four papers form a useful and interesting record of the successful development and operation of what still remains the first public television service in the world.
R. L. S.-R. 